ORP-52762

Revision 0

\title{
The Start of Ebullition in Quiescent, Yield-Stress Fluids
}

Prepared for the U.S. Department of Energy

Assistant Secretary for Environmental Management

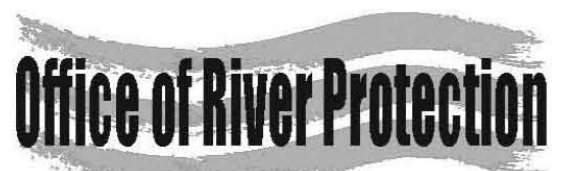

P.O. Box 450

Richland, Washington 99352 
ORP-52762

Revision 0

\section{The Start of Ebullition in Quiescent, Yield-Stress Fluids}

D. J. Sherwood

URS

Date Published

May 2012

Springer Science+Business Media

Published in

Rheologica Acta

Prepared for the U.S. Department of Energy

Assistant Secretary for Environmental Management

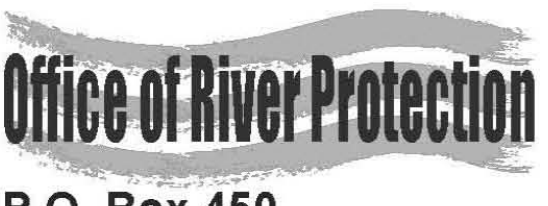

P.O. Box 450

Richland, Washington 99352

Copyright License

By acceptance of this article, the publisher and/or recipient acknowledges the U.S. Government's right to retain a non exclusive, royalty-free license in an to any copyright covering this paper.

APPROVED

By Julia Raymer at 9:14 am, Aug 30, 2012

\author{
A. E. Saez \\ Dept. of Chem. \& Env. Eng'g., The University of Arizona
}


ORP-52762

Revision 0

\section{LEGAL DISCLAIMER}

This report was prepared as an account of work sponsored by an agency of the United States Government. Neither the United States Government nor any agency thereof, nor any of their employees, makes any warranty, express or implied, or assumes any legal liability or responsibility for the accuracy, completeness, or any third party's use or the results of such use of any information, apparatus, product, or process disclosed, or represents that its use would not infringe privately owned rights. Reference herin to any specific commercial product, process, or service by trade name, trademark, manufacturer, or otherwise, does not necessarily constitute or imply its endorsement, recommendation, or favoring by the Unites States

Government or any agency thereof or its contractors or subcontractors. The views and opinions of authors expressed herein do not necessarily state or reflect those of the United States Government or any agency thereof.

This report has been reproduced from the best available copy.

Printed in the United States of America 


\title{
The Start of Ebullition in Quiescent, Yield-Stress Fluids
}

\author{
David J. Sherwood, ${ }^{a}$ A. Eduardo Sáez ${ }^{\text {b }}$ \\ ${ }^{\mathrm{a}}$ URS Corporation \\ Hanford Tank Waste Treatment and Immobilization Plant Project \\ 2435 Stevens Center Place \\ Richland, WA 99354 \\ ${ }^{\mathrm{b}}$ Department of Chemical and Environmental Engineering \\ The University of Arizona \\ Tucson, AZ 85721
}

Corresponding author: DJ Sherwood, djsherwo@bechtel.com 


\begin{abstract}
Non-Newtonian rheology is typical for the high-level radioactive waste (HLW) slurries processed in the Hanford Tank Waste Treatment and Immobilization Plant (WTP). Hydrogen and other flammable gases are generated in the aqueous phase by radiolytic and chemical reactions. HLW slurries have a capacity for retaining gas characterized by the shear strength holding the bubbles still. The sizes and degassing characteristics of flammable gas bubbles in the HLW slurries expected to be processed by the WTP are important considerations for designing equipment and operating procedures. Slurries become increasingly susceptible to degassing as the bubble concentration increases. This susceptibility and the process of ebullitive bubble enlargement are described here. When disturbed, the fluid undergoes localized flow around neighboring bubbles which are dragged together and coalesce, producing an enlarged bubble. For the conditions considered in this work, bubble size increase is enough to displace the weight required to overcome the fluid shear strength and yield the surroundings. The buoyant bubble ascends and accumulates others within a zone of influence, enlarging by a few orders of magnitude. This process describes how the first bubbles appear on the surface of a $7 \mathrm{~Pa}$ shear strength fluid a few seconds after being jarred.
\end{abstract}

Keywords: Yield stress fluid; Bubble enlargement; Coalescence; Ebullition 


\section{Introduction}

Bubbles form in liquid from chemical reactions or by decreasing pressure or increasing temperature after becoming supersaturated with dissolved gas. This condensation method (Exerowa and Kruglyakov 1998) for dispersing gas occurs whenever a liquid is boiled, when water vapor exsolves from magma during volcanic activity (Gaonach et al. 1996; Lovejoy et al. 2004), and in ocean sediments (Boudreau et al. 2001; Winterwerp et al. 2004) and peatlands (Glaser et al. 2004) after organic decomposition reactions saturate the liquid phase with dissolved gases such as methane and carbon dioxide. Solid particles dispersed in the liquid interact to provide a cohesive matrix (Richefeu et al. 2006; Nowak et al. 2005) which traps the gas bubbles. Cohesion is reflected in the shear strength (or yield stress) of the fluid or granular material that surrounds the bubble (Winterwerp et al. 2004).

The shear strength allows for trapping of bubbles of exsolved gas (Winterwerp et al. 2004; Gauglitz et al. 1996; Dubash and Frigaard 2004). Exsolution occurs by a first order phase transformation with the new gas phase separating from the liquid in stages: first by nucleation and growth, and second by ageing (Boudreau et al. 2001). Growth of nuclei reduces the concentration of dissolved gas in the nonequilibrium, supersaturated liquid, moving the system toward equilibrium. But the bubbles have surface free energy and therefore the system will not be in equilibrium until the gas collects into a single location, separated from the saturated liquid with a flat interface. Unlike typically simple liquids where bubbles rise as they are nucleated, fluids with shear strength allow both the non-competitive and second stage competitive growth processes to occur in situ. Rather large amounts of gas, $~ 30$ vol.\% in some cases, are then able to be retained in bubbles with diameters as large as $D_{\mathrm{b}} \sim 1 \mathrm{~cm}$ (Gauglitz et al. 1996). 
Radioactive waste slurries stored at the Hanford Site form bubbles from radiochemical reactions after the gases (e.g., hydrogen, methane, and nitrous oxide; Delegard 1980) reach their low solubility limits (Spinks and Woods 1976; Hu et al. 2002). The radioactive waste generates gas at rates of about $\dot{G} \approx 1 \mathrm{mmol} / \mathrm{m}^{3}$ day. By comparison, methane production from organic degradation reactions in marine sediment under harbors and lakes occurs in the range $\dot{G} \approx 1$ $\mu \mathrm{mol} / \mathrm{m}^{3}$ day to $100 \mathrm{mmol} / \mathrm{m}^{3}$ day (Winterwerp et al. 2004). A sudden release of bubbles form the Hanford waste containing flammable gas to the airspace outside the system can be hazardous, and significant engineering efforts are expended to mitigate this type of risk at the Hanford Tank Farms and WTP. There are similar concerns for humans living near coastal gas seeps of methane and hydrogen sulfide (Etiope et al. 2005).

Unlike volcanic systems where the volatile species (mainly water and carbon dioxide) are fairly soluble, several weight percent being dissolved at typical characteristically high pressures (Moore et al. 1998), Hanford slurry gases are sparingly soluble, less than about $10^{-5}$ weight percent for the typically near-ambient storage conditions (Hu et al. 2002), and so exsolve into bubbles. A large number of bubbles are then dispersed into the fluid, reaching levels at which the fluid can be considered a gas-liquid emulsion. The bubbles are retained until liberated because there is evidently a limiting, critical volume fraction of gas for yield-stress fluids. The precise nature of the internal disturbances which might initiate gas release is not known but, presumably, relate to fluctuations in local properties, or to the bubble population over ageing. Regarding the latter, after the nucleation and growth stage, the average bubble size increases as larger bubbles accumulate gas from the smaller bubbles in the late, ageing stage of phase separation (Sagui et al. 1998). Brief mechanical loads (i.e., a shock or jar) to the system's boundaries or intrusions into the system are examples of external disturbances. Stix (2007) notes that for volcanoes such 
triggers could be the rise of a larger gas bubble through a dispersion of smaller bubbles, or an earthquake.

Bubbles in a suddenly fluidized gas-liquid emulsion rise in concert and rapidly degas the system in a bubble cascade gas release event (Gauglitz et al. 1996). One of these was captured on video and a still image is shown in Figure 1. The fluid is an aqueous slurry of kaolin and bentonite clay particles simulating high-level radioactive waste with a yield stress of $7 \mathrm{~Pa}$. The tank is a $0.49 \mathrm{~m}^{3}$ vessel with $0.8 \mathrm{~m}$ depth provided with four pulse-jet mixers with tubes of 13.4 cm ID (see Meyer et al. 2005 and Russell et al. 2005, for more details on the apparatus). Oxygen from the decomposition of hydrogen peroxide in the aqueous phase was used to simulate the HLW slurry exsolved gases. All the gas exolved from the liquid accumulated in millions of bubbles of average diameter of $0.3 \mathrm{~cm}$. After the vessel was bumped, enlarged bubbles began emerging from the fluid. Figure 1 shows one of such bubbles. This particular type of ebullitive release occurs in homogeneous, viscoplastic fluids with shear strengths typically between $\tau_{\mathrm{y}} \approx 3$ $-70 \mathrm{~Pa}$ (Stewart et al. 2005); at the lower end of the range most bubbles are released and the system is effectively degassed. It is this lower range $\left(\tau_{y} \lesssim 30 \mathrm{~Pa}\right)$ where HLW slurries will be processed in the WTP. Understanding the ramifications of sudden ebullitive releases is important for sizing vessel headspaces and ventilation systems and developing operating and safety procedures.

Somewhat similar ebullitions occur in natural systems, such as saturated sediment (Winterwerp et al. 2004; Amos and Mayer 2006), peatlands (Tokida et al. 2005; Kellner et al. 2006), and in gas-driven eruptions for some types of volcanic activity (Gaonach et al. 1996; Lovejoy et al. 2004; Stix 2007), and lake and ocean activities (Zhang and Kling 2006). Strack et al. (2005) described what could be essentially the same behavior as "potential episodic release of $\mathrm{CH}_{4}$ via ebullition events." Some of these natural occurrences can, however, involve more 
complex processes than ebullition, and in the case of the eruptions, thrust the fluid upwards as exsolution of volatiles decreases the density, making it more buoyant (Pinkerton et al. 2002). Volcanic systems can contain large amounts of stored energy in condensed volatiles which is then liberated by exsolution as the rising magma depressurizes (Dobran 2001). But even quiescent volcanic activities such as degassing from the foam layer at a volcano chamber roof (Jauoart and Vergniolle 1989) are different from the ebullition considered here, because these volcanic systems are not homogeneous, and because the bubbles in HLW slurries occupy less than about a third of the total volume, so they are gas-liquid emulsions, as opposed to wet foams. Ebullition in HLW slurries occurs, furthermore, from relative bubble-liquid motion through a homogeneous emulsion; there is no accompanying ejection of the fluid itself and no sudden exsolution before the outgassing. This type of gas release is also different from the sudden degassing of stored radioactive waste at the Hanford Site by buoyant displacement events (Stewart et al. 2005; Meyer et al. 1997). The underground storage tanks are inhomogeneous systems, being filled with roughly half-liquid over half-sedimentary waste. Large portions of sediment shear away after becoming buoyant, then rise through the liquid to the surface and release gas.

Degassing of HLW slurries should not be affected significantly by slurry boundaries, since the behavior is observed without apparent difference in graduated cylinders (e.g. Gauglitz et al. 1996) and systems that are orders of magnitude larger (e.g. Figure 1). Internal mechanical structures also seem to play no role as the behavior occurs in systems without any. The conceptual system addressed by this work is as follows: Gas is generated and bubbles nucleate, grow, migrate, and undergo large-scale motion without need of interactions from the surroundings; although as noted here, external interactions prompt bubble motion. The need to improve understanding of bubble movement, particularly before yielding, was recently noted by 
Denn and Bonn (2011). The work reported here gives the most attention to the material behavior prior to global yielding, i.e., before the system becomes entirely fluid. Collective motions of first small and then larger groups of bubbles are identified, reflecting the local effects in small groups transitioning to large, global behavior.

Spherical bubbles with a diameter $D_{b}<D_{b}^{0}$, where

$$
D_{b}^{o} \approx \frac{5 \tau_{y}}{\rho g}
$$

are retained in Hanford HLW and simulants with shear strengths less than about $20 \mathrm{~Pa}$, where $\rho$ is the fluid density and $g$ the acceleration of gravity (Stewart et al. 1996). The videotaped fluid shown in Figure 1, having $\tau_{\mathrm{y}}=7 \mathrm{~Pa}$ and $\rho=1,200 \mathrm{~kg} / \mathrm{m}^{3}$, retained bubbles smaller than $D_{\mathrm{b}}^{\circ} \approx 0.3$ $\mathrm{cm}$. This estimate is consistent with the appearance of the largest bubbles held in a $\tau_{\mathrm{y}}=8 \mathrm{~Pa}$ Carbopol solution (Dubash and Frigaard 2004) (a clear fluid with easily seen bubbles, unlike the kaolin/bentonite slurry shown in Figure 1), as well as many other Hanford HLW slurries and experimental fluids (Gauglitz et al. 1996).

Retained gas bubbles attain their size during the ageing stage of phase separation.

Bouderau et al. (2001) developed a diffusion-reaction model for bubble growth in sediments due to exsolved methane. The model accounts for the dynamics of methane formation, diffusion through pore waters, incorporation of generated methane into a bubble, and bubble growth. Bubbles are assumed to be isolated and a uniform distributed methane generation in the liquid is considered. The average bubble radius $R_{\mathrm{b}}$ at time $t$ from gas generated at the volumetric rate $\dot{G}$ is given by

$$
R_{b}(t)^{2}-R_{b}^{0^{2}}=\frac{\varphi}{2 c_{b}}\left[\frac{\dot{G} d^{2}}{12}+D_{g}\left(c_{g}^{d}-c_{g}^{b}\right)\right] t
$$


where $R_{\mathrm{b}}^{0} \equiv R_{\mathrm{b}}(0), \varphi$ quantifies the tortuosity of the liquid path in the sediment, $D_{\mathrm{g}}$ is the diffusivity of gas molecules in the liquid phase, $c_{\mathrm{b}}$ is the molar concentration of gas in the bubble, which is equilibrated with dissolved gas having concentration $c_{\mathrm{g}}^{\mathrm{b}}$ at the bubble surface $\left(c_{\mathrm{b}}\right.$ $=K_{\mathrm{g}} c_{\mathrm{g}}^{\mathrm{b}}$, where $K_{\mathrm{g}}$ is Henry's law constant divided by the gas constant and absolute temperature), and $c_{\mathrm{g}}^{d}$ is the gas dissolved in the liquid at the average distance $d$ between the bubbles.

Figure 2 shows the geometry of a spatially periodic array of bubbles in the gas-liquid emulsion (Pinkerton et al. 2002; Proussevitch and Sahagian 1998; Lensky et al. 2004; Liu and Zhang 2000) where the fluid is arranged as a two-dimensional array of hexagons surrounding bubbles spaced a distance $d$ apart. The average bubble size $R_{\mathrm{b}}$ and spacing $d$ are constrained by the number of bubbles per unit volume $N_{\mathrm{v}}$ and their volume fraction $f_{\mathrm{b}}$ :

$$
d=\left(\frac{4}{3} \pi N_{v}\right)^{-1 / 3}=\frac{R_{b}}{f_{b}^{l / 3}}
$$

The average bubble size does not increase indefinitely, which is not accounted for by Eq. 2. Continuous gas production increases both $N_{\mathrm{v}}$ and $R_{\mathrm{b}}$ and therefore the volume fraction of bubbles, $f_{\mathrm{b}}$; and this decreases the spacing $d$ between bubbles. Slurries with modest shear strengths like the fluid of Figure 1 have limiting bubble fractions which increase with the shear strength (Gauglitz et al. 1996): as the bubble concentration increases the system becomes increasingly susceptible to spontaneous degassing.

A model is presented and evaluated here to describe how a dense array of bubbles is destabilized and subsequently cascades. First the creeping flow preceding bubble rise is evaluated for prospective bubble enlargement using a variation of the neighbor switching mechanism (Lundberg et al. 2008). The resulting estimate is then taken as the initial condition in a model where a buoyant bubble grows by accumulating others in its path while rising. The size 
it attains on the surface is compared to how the fluid appears on Figure 1, which shows a single emerging bubble just before ebullition begins.

\section{Theory}

The system shown in Figure 1 was susceptible to ebullition with a 20 vol.\% gas content $\left(f_{\mathrm{b}} \approx\right.$ 0.2) since this happened less than a minute after the vessel was bumped. Equation 1 indicates that the $7 \mathrm{~Pa}$ shear strength would have allowed the slurry to retain gas bubbles with diameters smaller than $D_{\mathrm{b}}^{0} \approx 0.3 \mathrm{~cm}$. Taking this value as an average, Eq. 3 estimates that the average distance between bubbles is $d \approx 0.3 \mathrm{~cm}$, a rather dense packing, typical for Hanford HLW slurries (Gauglitz et al. 1996). Coalescence becomes an important enlargement mechanism when bubble fractions are larger than about $f_{\mathrm{b}} \approx 0.18$ (Bai et al. 2008). This type of bubble enlargement features prominently in the process proposed here to explain the bubble size shown in Figure 1. There are two regimes: bubbles migrate together by creeping, a type of sub-yield flow, and bubbles liberated from the fluid after yielding rise and encounter those higher up. These mechanisms are explored next considering that the fluid rheology is time dependent (i.e. the fluid exhibits thixotropic behavior).

A bubble having radius $R_{\mathrm{b}}$ from gas of negligible density rises in a Newtonian fluid with viscosity $\eta$ at the terminal velocity (Stokes' law)

$$
v_{b}^{\infty}=\frac{2 \rho R_{b}^{2} g}{9 \eta}
$$

in the creeping flow regime. But the viscosity varies with shear rate for non-Newtonian fluids, giving them the appearance of having a shear strength $\tau_{y}$ as a result. A bubble or other particle moving through such a fluid has essentially no effect on the material outside a surface around its immediate vicinity. The shear strength effect arises from interactions between small suspended 
particles, which produce microstructures (e.g. Marangoni and Rogers 2003; Laxton and Berg 2006; Coussot et al. 1993). The amount of interaction can be characterized by a parameter related to the extent of linking between the particles: the structure factor, $s$, that is used to express the dependence of shear viscosity on shear rate, $\dot{\gamma}$,

$$
\eta(s)=\eta_{0}\left(1+s^{n}\right)
$$

where $s=s(\dot{\gamma})$ and $n \geq 1$ (Ferroir et al. 2004). When there is no structure, $s=0$, and the viscosity is constant, $\eta=\eta_{0}$. For example, $n=1.02$ for suspensions of laponite and bentonite clay particles in aqueous systems (Ferroir et al. 2004). The amount of structure $s$ is determined from the rate equation

$$
\dot{s}=\left\{\begin{array}{l}
\text { restructuring } \\
\text { rate }
\end{array}\right\}-\left\{\begin{array}{l}
\text { destructuring } \\
\text { rate }
\end{array}\right\}=\frac{1}{\theta}-\operatorname{cs} \dot{\gamma}
$$

where $\theta$ and $c$ are properties of the liquid and solid phases, $\theta$ is a characteristic time governing structure formation and $c$ is dimensionless.

The region where bubble motion disrupts particle structures is about equal to the bubble volume (Ferroir et al. 2004). This part of the fluid is called the zone of influence; it is a cylinder with height $h_{\mathrm{z}}$ in the direction of bubble rise, and diameter $D_{\mathrm{z}}\left(\sim D_{\mathrm{b}}\right)$ perpendicular to it. There is also a characteristic thickness of shear, $\Delta_{z} \approx v_{b} / \dot{\gamma}$ associated with the bubble rise velocity $v_{\mathrm{b}}$ and the shear rate. Equation (6) can then be written as

$$
\frac{d s}{d t} \approx \frac{1}{\theta}+\left[\frac{s_{0}}{h_{z}}-\left(\frac{c}{\Delta_{z}}+\frac{1}{h_{z}}\right) s\right] v_{b}
$$

where $s_{0}=s(t=0)$ is the initial structure and the bubble rise velocity is given by using the nonNewtonian viscosity from Eq. (5) into Stokes law, 


$$
v_{b}=\frac{2 \rho R_{b}^{2} g}{9 \eta(s)}=\frac{v_{b}^{\infty}}{1+s^{n}}
$$

with $v_{\mathrm{b}}^{\infty}$ given by Eq. 4 with $\eta=\eta_{0}$. The bubble rise velocity therefore decreases with increased structure $s: v_{\mathrm{b}}$ is always less than $v_{\mathrm{b}}^{\infty}$ so long as $s>0$. If $s$ continuously increases with time, then $v_{\mathrm{b}}$ decreases and the bubble is effectively trapped. But if $s$ reaches a constant, steady-state value $s_{\mathrm{ss}}$, then the bubble rise velocity will also reach a steady-state value, $v_{\mathrm{b}}^{\mathrm{ss}}=v_{\mathrm{b}}^{\infty} /\left(1+s_{\mathrm{ss}}\right)$. The bubble then migrates at the constant velocity $v_{\mathrm{b}}^{\text {ss }}$ differing only from a structureless (Newtonian) slurry by the reducing factor $\left(1+s_{\mathrm{ss}}\right)$.

The previous equations ( 7 and 8) can be expressed in dimensionless form using dimensionless distance

$$
H=\frac{h}{h_{z}}
$$

and dimensionless time

$$
T=\frac{t}{\theta}
$$

so that equations (7) and (8) can be rewritten as

$$
\begin{aligned}
& \frac{d s}{d T}=1+\left[s_{0}-(\beta+1) s\right] \frac{d H}{d T} \\
& \frac{d H}{d T}=\frac{Y^{\infty}}{1+s^{n}}
\end{aligned}
$$

where

$$
\begin{aligned}
& \beta=\frac{c h_{z}}{\Delta_{z}} \\
& Y^{\infty}=\frac{v_{b}^{\infty} \theta}{h_{z}}
\end{aligned}
$$


Figure 3 shows results of the numerical solution of Eqs. (11) and (12) for $s_{0}=10, \beta=1, n$ $=1.02$, and various values of $Y^{\infty}$, plotted as dimensionless bubble velocity $(\mathrm{dH} / \mathrm{dT})$ vs.

dimensionless bubble vertical distance (H). Clearly, there is a critical value of $Y^{\infty}$, in this case $Y_{c}^{\infty}=0.572$, above which the bubble velocity reaches an asymptotic value (terminal velocity), which means that the bubbles will keep ascending towards the fluid surface. On the other hand, for $Y^{\infty}<Y_{c}^{\infty}$, the bubble velocity will continuously decrease and, given enough fluid depth, the bubble eventually will stop and become trapped. A necessary condition for achieving a terminal velocity is the existence of a steady state in the fluid structure. From inspection of equation (11) and use of equation (12), it is clear that this will happen whenever there is an $s>0$ that satisfies

$$
1+\left[s_{0}-(\beta+1) s\right] \frac{Y^{\infty}}{1+s^{n}}=0
$$

This equation can be rearranged as follows

$$
\psi(s)=s^{n}-(\beta+1) Y^{\infty} s+1+s_{0} Y^{\infty}=0
$$

and $(n>1)$

$$
\psi^{\prime}(s)=n s^{n-1}-(\beta+1) Y^{\infty}
$$

Clearly, $\psi(0)>0$ and $\psi^{\prime}(0)<0$. Since $\psi(s)$ increases monotonically at large values of s, $\psi$ has an absolute minimum at

$$
s_{m}=\left[\frac{(\beta+1) Y^{\infty}}{n}\right]^{\frac{1}{n-1}}
$$

Hence, the only way for $\psi(s)$ to have at least a positive root is if $\psi\left(s_{m}\right)<0$. This means that the critical point is given by the condition $\psi\left(s_{m}\right)=0$, which implies

$$
\left[\frac{(\beta+1) Y_{c}^{\infty}}{n}\right]^{\frac{n}{n-1}}-(\beta+1) Y_{c}^{\infty}\left[\frac{(\beta+1) Y_{c}^{\infty}}{n}\right]^{\frac{1}{n-1}}+1+s_{0} Y_{c}^{\infty}=0
$$


For given $n$ and $s_{0}$, this equation relates $Y_{c}^{\infty}$ to $\beta$. The relation is plotted in Figure 4 for $n=1.02$ and $s_{0}=10$.

For the special case $n=1$, equations (11) and (12) can be solved analytically and the critical point is given by

$$
Y_{c}^{\infty}=\frac{1}{\beta+1}
$$

(independent of $s_{0}$ ).

Flow is laminar-like and confined between static regions when complex fluids are in transition from a quiescent state (Coussot et al. 1993). The two-dimensional viscoplastic foam (Princen 1983) is often used as an analog for flowing condensed matter (Morral and Ashby 1974), particularly following an hexagonal array geometry (Khan and Armstrong 1986; Kern et al. 2004; Cantat and Delanney 2005). The sub-yielding flow shown in Figure 3 can be modeled by having neighboring cells in the array switch their nearest neighbors (Morral and Ashby 1974). Integrating a second, minor phase such as bubbles into the material is also possible (Holm et al. 1977). Figure 5 shows a hexagonal array undergoing neighbor switching while also dragging two particles of the dispersed phase together during second phase coarsening of microduplex alloys in superplastic flow. In the present case, of course, the minor phase is bubbles. Bubbles move towards one another by the hydrodynamic forces causing relative translations of the neighboring fluid elements. Khan and Armstrong (1986) presented an analysis of the geometry and stresses/strains on the hexagonal array in the intermediate configurations, while Besson and Debrégeas (2007) analyzed the dynamics of the film that forms and migrates between the two bubbles. Liu and Zhang (2000) observed coalescence or near-coalescence of bubble pairs in most of their samples. The rate at which liquid films are thinned and then eliminated as coalescence occurs depends on physicochemical properties of the slurry but, as Gaonach et al. 
(1996) note, "bubbles with such internal films will be able to participate further on in the cascade growth coalescence."

Analyzing the system along the lines of the work by Holm et al. (1977), the frequency with which bubble contacts occur should be proportional to the shear rate caused by the triggering event, $\dot{\gamma}_{0}$, and the number of bubbles per unit volume $N_{\mathrm{v}}$. Then the number of bubbles per unit volume decreases by coalescence at the rate

$$
\dot{N}_{v}=-\kappa \dot{\gamma}_{0} N_{v}
$$

where $\kappa$ is a factor reflecting the geometrical arrangement of the emulsion and the efficiency of coalescence. Integrating Eq. 6 from an initial value $N_{v}^{0}=3 f_{b}^{0} / 4 \pi R_{b}^{0^{3}}$ gives

$$
N_{v}=N_{v}^{0} \exp \left(-\kappa \dot{\gamma}_{0} t\right)
$$

Unlike real solids for which $\dot{\gamma}_{0}$ can be treated as a constant when stress is continuously applied to the test specimen, with fluids, even quiescent non-Newtonian ones, the shear rate from an initial disturbance is likely to vary significantly with both time and position. Constant values also misrepresent the concept that neighbor switching reactions require activation in sub-yielded (creeping) flow. Buoyant bubbles have enough energy to yield the fluid and therefore do not require activation. Creeping bubbles encountering one another can coalesce and then become buoyant. This shifts the flow-curve of the resulting larger and buoyant bubble from one that is below $Y_{c}^{\infty}$ to one above it, as shown by the illustration in Figure 4. Modest bubble enlargement could cause this shift. In fact, all the curves for creeping flow shown in Figure 3 (those under the bifurcation) have radii large enough so that coalesced gemini become buoyant, i.e. have a flowcurve above the bifurcation. 
Stewart et al. (1996) provided a simple enlargement model for bubbles ascending in a yielded fluid: The bubble volume $V_{\mathrm{b}}=\pi D_{\mathrm{b}}^{3} / 6$ increases from depressurizing and by collecting other bubbles within a region twice its diameter while rising from depth $h$ with head $P^{0}+\rho g h$,

$$
\frac{d V_{b}}{d h}=\frac{\rho g V_{b}}{P^{0}+\rho g h}+\frac{1}{4} \pi\left[2\left(\frac{6 V_{b}}{\pi}\right)^{1 / 3}+D_{b i}\right]^{2} f_{b}
$$

where $D_{b i}$ is the diameter of the bubble at the start of the ascent. Except for the first term due to decompressive expansion, this relationship is similar to the increase in size of raindrops as they descend and accumulate others falling at different speeds (Seinfeld and Pandis 1998, Chapter 15). Equation (23) assumes an accretion efficiency of unity; i.e., whenever contact is made, coalescence results. A value of $2^{1 / 3} D_{b}^{0}$ from coalesced gemini each with diameter $D_{b}^{0}$ can be used for coalesced bubble size, as suggested above. The volume of the bubble rising from an initial depth $h=L$ where $D_{b}=D_{b i}$, to the surface $h=0$ is then

$$
V_{b}(0)=\int_{L}^{0} \frac{d V_{b}}{d h} d h
$$

and its diameter on the surface is

$$
D_{b}(0)=\left[\frac{6 V_{b}(0)}{\pi}\right]^{1 / 3}
$$

The results of numerically integrating Eq. 23 as indicated by Eq. 24 are shown in Figure 6. With the initial diameter of a free bubble as $D_{b i}=0.4 \mathrm{~cm}$, and estimating that it comes from half-way down the vessel (Figure 1), $L=0.4 \mathrm{~m}$, the bubble size emerging from the fluid is predicted to increase about two orders of magnitude to $D_{\mathrm{b}}(0) \approx 20 \mathrm{~cm}$. This is the right order of magnitude to account for the size of bubbles appearing at the fluid surface (Figure 1). 


\section{Discussion}

Bubbles nucleated in yield-stress fluids are kept in place long enough for the late stage ageing processes of the phase transformation to occur. In a first-order phase transformation bubbles are nucleated and then grow by absorbing gas dissolved in the liquid; this is the first stage of phase separation (Kashchiev 2000). Bubbles grow competitively (Ostwald ripening, Eq. 2) and by coalescence for high $f_{\mathrm{b}}$ in the subsequent ageing stage. It is suggested here that the fluid shear strength allows the bubble population to mature so that the average size and concentration are increased enough for a late stage coalescence (Figure 5) to produce a buoyant bubble (flow curve above the bifurcation of Figure 3). Two bubbles merge after creeping together from a relatively gentle disturbance, either spontaneously (e.g., an internal disturbance from fluctuations or noise) or externally induced. The diameter $D_{b i}$ of this first buoyant bubble gives the initial condition for integrating Eq. 23. As the bubble rises, it absorbs others in its path and enlarges. Figure 6 shows that, except for the bubble volume fraction $f_{\mathrm{b}}$, these results are not particularly sensitive to fluid properties; the lack of dependency on $D_{b i}$ for higher $f_{\mathrm{b}}$ is noteworthy. As the bubble ascends and accumulates other bubbles those at its periphery may be disturbed and liberated, producing a plume of rising bubbles. Something like this starts the spontaneous degassing of HLW simulants in bench-scale (Gauglitz et al. 1996; Stewart et al. 2005) and pilot-scale (Figure 1) systems. For example, a bubble cascade was observed in bentonite clay with $10 \mathrm{~Pa}$ shear strength shortly after a single, several-millimeter diameter bubble became buoyant, yielded the surrounding fluid, and rose to the surface (Stewart et al. 2005).

There are many potential causes for ebullition being triggered in natural systems (Stix 2007; Rudolph and Manga 2010). "Shaking-induced bubble mobilization" was evaluated and dismissed by Rudolph and Manga (2010) for the case of a mud volcano with very high viscosity, 
but the gas release shown in Figure 1 began shortly after the test vessel was bumped and therefore such a mechanical disturbance is the most plausible explanation.

Bubble coalescence is typically treated as a ballistic process in fluid flow (e.g. Lovejoy et al. 2004) with the reaction rate proportional to a concentration term that is squared, reflecting the collision of two species into an active complex, i.e., Smoluchowski kinetics (Okamura et al. 2006). This is for the case where reactants are moving independently of their surroundings. Here, on the other hand, nearby bubbles are dragged together by the relative motion of a surrounding primary phase, i.e., the neighbor switching mechanism (Morral and Ashby 1974; Princen 1983) adapted to include coalescence of a dispersed phase (Holm et al. 1997). Since the two gemini bubbles merge into a single bubble for the final state, the kinetics for $N_{\mathrm{v}}$ given by Eq. 21 reflect a first order decay process. Equation 21 is also proportional to the shear rate, as originally suggested. This is an assumption, but it is probably a good one, as indicated by experimental work on a gas-liquid system with similar bubble fraction $\left(f_{\mathrm{b}}=20 \mathrm{vol} \%\right)$ sheared at $\dot{\gamma}=0.01 \mathrm{~s}^{-1}$ (Okamura et al. 2006).

It is well known that liquids supersaturated with dissolved gas like carbonated beverages nucleate numerous bubbles when agitated, and if the liquid is in a sealed container which is then opened, under-pressurized bubbles enlarge and rise rapidly, creating an overflowing foam (Rothery et al. 2007). Thick foam layers may also play a significant role during basaltic eruptions (Jaupart and Vergniolle 1988). Crucially, ebullition in yield stress fluids does not begin at numerous sites like carbonated beverages, or require a restricted boundary for bubbles to collect as in basaltic eruptions. Bubbles in non-Newtonian fluids are effectively trapped by the material itself during the nucleation and growth stage and also during the later coarsening stage until their size and volume fraction are so high the population becomes prone to release. Then, once unsettled by a disturbance, gemini bubbles coalesce into buoyant offspring, enlarging as 
they ascend into a medium dense enough with other bubbles to make additional liberations likely, producing a cascade of mobile bubbles. Foaming does not play a role in this process.

Rudolph and Manga (2010) note that shaking-induced bubble mobilization could be a viable ebullition mechanism if coalescence happens quickly, meaning frequent and successful encounters. This requires that the characteristic time scale for bubble interactions

$$
t_{c}=\frac{2 \eta}{\rho g D_{b i} f_{b}}
$$

is appropriately shorter than the time needed to ascend from initial depth $h=L$ to the surface $h=$ 0 ,

$$
t_{a}=\int_{L}^{0} \frac{d h}{v_{b}}
$$

that is, $t_{\mathrm{c}} \ll t_{\mathrm{a}}$. For the highly viscous $\eta \sim 10^{6} \mathrm{~Pa}$ s mud volcano, $t_{\mathrm{c}}>1$ week for $D_{b i} \sim 1 \mathrm{~cm}$ and $f_{\mathrm{b}}$ $\sim 1$ vol.\%, which is far too long (Rudolph and Manga 2010). The HLW simulant of Figure 1 is much less viscous, $\eta \sim 10^{-2} \mathrm{~Pa} \cdot \mathrm{s}$, so that $t_{\mathrm{c}}$ « $1 \mathrm{~s}$. This constraint was justifiably neglected here with the assumption that all bubble encounters succeed as coalescings.

Rudolph and Manga (2010) also suggest that bubbles trapped in a yield stress fluid can be mobilized when seismic shaking "temporarily weakens the material." This thought is made more definite here with the neighbor switching mechanism for creeping flow, which induces bubble coalescence (Figure 5), resulting in a buoyant offspring (Figure 3), and enlargement as the offspring collect other bubbles in their path (Figure 6). The path traversed by mobile bubbles is a fluidized or weakened channel through an otherwise yield-stress fluid. As more bubbles are mobilized, these channels consume the entire fluid volume until all the bubbles are released, at which point flow stops and the fluid shear strength can begin to increase again as the particles rebuild the microstructure. 


\section{Concluding Remarks}

Bubble coalescence is an important feature of ebullition and is the principal cause of enlargement and gas release for the near-surface conditions in radioactive waste storage and processing systems. The pilot-scale test vessel of Figure 1 was filled with a rheological simulant of what is expected to be a typical HLW stream for the WTP. This slurry of clay particles with $7 \mathrm{~Pa}$ shear strength released the bubbles filling it shortly after being bumped. Such bubble cascade gas releases were also observed in numerous laboratory experiments. Here it is suggested that a chain reaction is started when at least one active center results from an external disturbance although internal fluctuations potentially could have the same effect. The active center is modeled as an array of neighboring fluid elements surrounding a bubble pair. They move relative to one another in the creeping flow caused by the disturbance, dragging the bubbles together which then coalesce, as shown in Figure 5. If the single bubble emerging from this event is buoyant, i.e., it is located in the mobile bubble region of Figure 4, and the bubble concentration is high enough, then it can nudge another bubble pair into coalescing as it rises. This could create a peripheral disturbance some distance away large enough to activate another bubble pair. Bubbles in free ascent accumulate those in their path and enlarge. The enlargement estimated in this work is the order of magnitude suggested by Figure 1. This image shows a single bubble at the fluid surface before it becomes roiled by the numerous bubbles set into motion after the initial few were freed. It is expected that slurries having shear strengths of less than about $30 \mathrm{~Pa}$ would be almost completely fluidized by this type of bubble cascade with practically their entire gas inventory being released in just a few seconds. WTP ventilation systems either must be prepared to dilute this amount of slurry gas to safe, non-flammable levels in the vessel headspaces, or have mixing systems that periodically bump vessel contents to keep bubble concentrations lower than what is susceptible to spontaneous release. 


\section{Acknowledgements}

We would like to thank Dr. Gary L. Smith of the Pacific Northwest National Laboratory for providing the video (Figure 1) and pointing out the significance of this type of gas release for the WTP Project. We are also thankful to Dr. Walter Tamosaitis (URS Corporation) and Mr. Garth Duncan (Bechtel National, Inc.) for their support. 


\section{References}

Amos RT, Mayer KU (2006) Investigating ebullition in a sand column using dissolved gas analysis and reactive transport modeling. Environ Sci Technol 40: 5361-5367.

Bai L, Baker DR, Rivers M (2008) Experimental study of bubble growth in Stromboli basalt melts at 1 atm. Earth Planet Sci Lett 267: 533-547.

Besson S, Debrégeas G (2007) Statics and dynamics of adhesion between two soap bubbles. Eur Phys J E 24: 109-117.

Boudreau BP, Gardiner BS, Johnson BD (2001) Rate of growth of isolated bubbles in sediments with a diagenetic source of methane. Limnol Oceanogr 46: 616-622.

Cantat I, Delannay R (2005) Dissipative flows of 2D foams. Eur Phys J, 18: 55-67.

Coussot P, Leonov AI, Piau JM (1993) Rheology of concentrated dispersed systems in a low molecular weight matrix. J Non-Newt Fluid Mech 46: 179-217.

Delegard CH (1980) Laboratory studies of complexed waste slurry growth in tank 241-SY-101, RHO-LD-124. Rockwell Hanford Operations, Richland WA.

Denn MM, Bond D (2011) Issues in the flow of yield-stress liquids. Rheol Acta 50: 307-315.

Dobran F (2001) Volcanic processes: Mechanisms in material transport. Kluwer Academic / Plenum Publishers, New York.

Dubash N, Frigaard I (2004) Conditions for static bubbles in viscoplastic fluids. Phys Fluids 16: 4319-4330.

Etiope G, Papatheodorou G, Christodoulou D, Favali P, Ferentinos G (2005) Gas hazard induced by methane and hydrogen sulfide seepage in the NW Peloponnesus petroliferous basin (Greece). Terr Atm Ocean Sci 16: 897-908. 
Exerowa D, Kruglyakov PM (1998) Foams and foam films: Theory, experiment, application. Elsevier, Amsterdam.

Ferroir T, Huynh HT, Chateau X, Coussot P (2004) Motion of a solid object through a pasty (thixotropic) fluid. Phys Fluids 16: 594-601.

Gaonach H, Lovejoy S, Stix J, Scherzter D (1996) A scaling growth model for bubbles in basaltic lava flows. Earth Planet Sci Lett 139: 395-409.

Gauglitz PA, Konynenbelt JH, Rassat SD, Tingey SM, Bredt PR, Mendoza DP (1996)

Mechanisms of gas bubble retention and release: Results for Hanford Waste Tanks 241-s-102 and 241-sy-103 and single-shell tank simulants, PNNL-11298. Pacific Northwest National Laboratory, Richland WA.

Glaser PH, Chanton JP, Morin P, Rosenberry DO, Siegel DI, Ruud O, Chaser LI, Reeve AS (2004) Surface deformations as indicators of deep ebullition fluxes in a large northern peatland. Global Biogeochem Cycles 18: GB1003.

Holm K, Embury JD, Purdy GR (1977) The structure and properties of microduplex Zr-Nb alloy. Acta Metall 25: 1191-1200.

Hu TA, Barker SA, Hedengren DC, Kufahl MA (2002) Steady-state flammable gas release rate calculation and lower flammability level evaluation for Hanford tank waste. RPP-5926, CH2M Hill, Richland, WA.

Jaupart C, Vergniolle S (1988) Laboratory models of Hawaiian and Strombolian eruptions. Nature 331: 58-60.

Jaupart C, Vergniolle S (1989) The generation and collapse of a foam layer at the roof of a basaltic magma chamber. J Fluid Mech 203: 347-380. 
Kashchiev D (2000) Nucleation: Basic theory with applications, Butterworth-Heinemann, Oxford.

Khan SA, Armstrong RC (1986) Rheology of foams: I. Theory for dry foams. J Non-Newt Fluid Mech 22: 1-22.

Kellner E, Baird AJ, Oosterwoud M, Harrison K, Waddington JM (2006) Effect of temperature and atmospheric pressure on methane $\left(\mathrm{CH}_{4}\right)$ ebullition from near-surface peats. Geophys Res Lett 33: L18405.

Kern N, Weaire D, Martin A, Hutzler S, Cox SJ (2004) Two-dimensional viscous froth model for foam dynamics. Phys Rev E 70: 041411.

Laxton PB, Berg JC (2006) Relating clay yield stress to colloidal parameters. J Colloid Interface Sci 296: 749-755.

Lensky NG, Navon O, Lyakhovsky V (2004) Bubble growth during decompression of magma: Experimental and theoretical investigation. J Volcanol Geotherm Res 129: 7-22.

Liu Y, Zhang Y (2000) Bubble growth in rhyolitic melt. Earth Planet Sci Lett 181: 251-264.

Lovejoy S, Gaonach H, Schertzer D (2004) Bubble distributions and dynamics: the expansioncoalescence equation. J Geophys Res 109: B11203.

Lundberg M, Krishan K, Xu N, O’Hern CS, Dennin M (2008) Reversible plasticity in amorphous materials. Phys Rev E 77: 041505.

Marangoni AG, Rogers MA (2003) Structural basis for the yield stress in plastic disperse systems. Appl Phys Lett 82: 3239-3241. 
Meyer PA, Brewster ME, Bryan SA, Chen G, Pederson LW, Stewart CW, Terrones G (1997) Gas retention and release behavior in Hanford double-shell waste tanks. PNNL-11536, Rev. 1, Pacific Northwest National Laboratory, Richland WA.

Meyer PA, Kurath DE, Stewart CW (2005) Overview of the pulse jet mixer non-Newtonian scaled test program. PNWD-3677, WTP-RPT-127, Battelle - Pacific Northwest Division, Richland, WA.

Moore G, Vennemann T, Carmichael ISE (1998) An empirical model for the solubility of $\mathrm{H}_{2} \mathrm{O}$ in magmas to 3 kilobars. Am Mineral 83: 36-42.

Morral JE, Ashby MF (1974) Dislocated cellular structures. Acta Metall 22: 567-575.

Nowak S, Samadani A, Kudrolli A (2005) Maximum angle of stability of a wet granular pile. Nature Physics 1: 50-52.

Okamura S, Nakamura M, Tsuchiyama A (2006) Shear-induced bubble coalescence in rhyolitic melts with low vesicularity. Geophys Res Lett 33: L20316.

Pinkerton H, Wilson L, Macdonald R (2002) The transport and eruption of magma from volcanoes: A review. Contemporary Physics 43: 197-210.

Princen HM (1983) Rheology of foams and highly concentrated emulsions. I. Elastic properties and yield stress of a cylindrical model system. J Colloiod Interface Sci 91: 160-175.

Proussevitch AA, Sahagian DL (1998) Dynamics and energetics of bubble growth in magmas: Analytical formulation and numerical modeling. J Geophys Res 103: 18,223-18,251.

Richefeu V, El Youssoufi MS, Fadjaï F (2006) Shear strength properties of wet granular materials. Phys Rev E 73: 051304. 
Rothery DA, Sumner JJ, Spieler O, Dingwell DB (2007) Impact vesiculation — A new trigger for volcanic bubble growth and degassing. eEarth Discuss 2: 151-167.

Rudolph ML, Manga M (2010) Mud volcano response to the 4 April 2010 El Mayor-Cucapah earthquake. J Geophys Res 115: B12211.

Russell RL, Rassat SD, Arm ST, Fountain MS, Hatchell BK, Stewart CW, Johnson CD, Meyer PA, Guzman-Leong CE (2005) Gas retention and release in hybrid pulse jet mixed tanks containing non-Newtonian waste simulants. PNWD-33552, Battelle - Pacific Northwest Division, Richland, WA.

Sagui C, O'Gorman DS, Grant M (1998) Nucleation, growth and coarsening in phase-separating systems. Scanning Microscopy 12: 3-8.

Seinfeld JH, Pandis SN (1998) Atmospheric chemistry and physics. John Wiley \& Sons, New York.

Spinks JWT, Woods RJ (1976) An introduction to radiation chemistry. $2^{\text {nd }}$ ed, John Wiley \& Sons, New York.

Stewart CA, Meyer AP, Brewster ME, Recknagle KP, Gauglitz PA, Reid HC, Mahoney LA (1996) Gas retention and release behavior in Hanford single-shell waste tanks. PNNL-11391, Pacific Northwest National Laboratory, Richland WA.

Stewart CA, Hartley SA, Meyer PA, Wells BE (2005) Predicting peak hydrogen concentrations from spontaneous gas releases in Hanford Waste Tanks. PNNL-15238, Pacific Northwest National Laboratory, Richland WA.

Stix J (2007) Stability and instability of quiescently active volcanoes: The case of Masaya, Nicaragua. Geology 35: 535. 
Strack M, Kellner E, Waddington JM (2005) Dynamics of biogenic gas bubbles in peat and their effects on peatland biogeochemistry. Global Biogeochem Cycles 19: GB1003.

Tokida T, Miyazaki T, Mizoguchi M (2005) Ebullition of methane from peat with falling atmospheric pressure. Geophys Res Lett 32: L13823.

Winterwerp JC, van Kesteren WGM (2004) Introduction to the physics of cohesive sediment in the marine environment. Elsevier, Amsterdam.

Zhang Y, Kling GW (2006) Dynamics of lake eruptions and possible ocean eruptions. Ann Rev Earth Planet Sci 34: 293-324. 


\section{Figure captions}

Figure 1. Appearance of a bubble on the surface of a bumped vessel. The still frame shows a bubble of about $6 \mathrm{~cm}$ in diameter emerging from a $0.49 \mathrm{~m}^{3}$ vessel containing an aqueous slurry of kaolin and bentonite particles. Before the perturbation, the fluid was stationary and contained millions of oxygen bubbles generated by $\mathrm{H}_{2} \mathrm{O}_{2}$ decomposition of average diameter $0.3 \mathrm{~cm}$. Bubble coalescence must have occurred to generate the observed bubble since the vessel depth $(0.8 \mathrm{~m})$ is too shallow for significant enlargement by decompression.

Figure 2. Models for spatially periodic bubble arrays in gas-liquid emulsions; (a) bubbles are surrounded by a spherical region of fluid of diameter $d$; (b) each bubble is inside a hexagon that inscribes the circles in (a).

Figure 3. Bubble rise velocity as a function of vertical distance in a yield-stress fluid as represented by the model developed by Ferroir et al. (2004). Parameters used in the simulation: $s^{0}=10 ; \beta=1 ; n=1.02$ (aqueous suspension of laponite and bentonite clays); values of $Y^{\infty}$ shown. For $Y^{\infty} \geq 0.572$, the ascending speed reaches an asymptotic value, indicating that bubbles will continue to rise until they disengage from the suspension. For $Y^{\infty}<0.573$, bubble velocity decreases monotonically so that, given enough fluid depth, bubbles will be trapped.

Figure 4. Bubble retention map for $s^{0}=10 ; \beta=1 ; n=1.02$. The solid line represents the critical value of $Y^{\infty}$ above which bubbles will reach a terminal velocity (mobile bubbles) and below which the bubble velocity keeps decreasing with vertical distance (trapped bubbles). The red line illustrates a regime change when two bubbles of radius $R_{b 1}$ with $Y^{\infty}=0.5$ (point A) coalesce to form a single bubble of radius $R_{b 2}$ : at constant pressure (i.e. neglecting surface tension effects), $R_{b 2} / R_{b 1}=2^{1 / 3}$, which increases $Y^{\infty}$ to 0.79 (point B), since $Y^{\infty} \sim R_{b}{ }^{2}$. This shows how bubbles that potentially may become trapped will lead to ebullition upon coalescence. 
Figure 5. Bubble coalescence from neighbor switching reactions. Hexagons represent the continuous phase, a quasi-static yield-stress fluid, and the small, lightly-shaded circles represent the dispersed second phase (bubbles). The hexagons undergo neighbor switching: i. Initial condition with tensile stress and equivalent shear stress (parallelogram). ii. Fluid elements and bubbles respond elastically to the stress. iii. Fluid elements have stretched to a maximum extent and bubbles have contacted. iv. Final condition: boundaries have relaxed to minimize surface area and the bubbles have merged/relaxed.

Figure 6. Ebullitive bubble enlargement from cascade coalescence. Bubbles enlarge in a cascade because they collide inelastically with one another and coalesce. Fluid density is $\rho=1,200$ $\mathrm{kg} / \mathrm{m}^{3}$ with various volume fractions. In all four cases shown the bubble cascade begins with a bubble having diameter $D_{\mathrm{bi}}$, rising from a depth $h=L=0.4 \mathrm{~m}$ to the surface $h=0$, enlarging to attain the value $D_{b}(0)$ (bubble diameter at the surface), which increases as the initial value increases. 


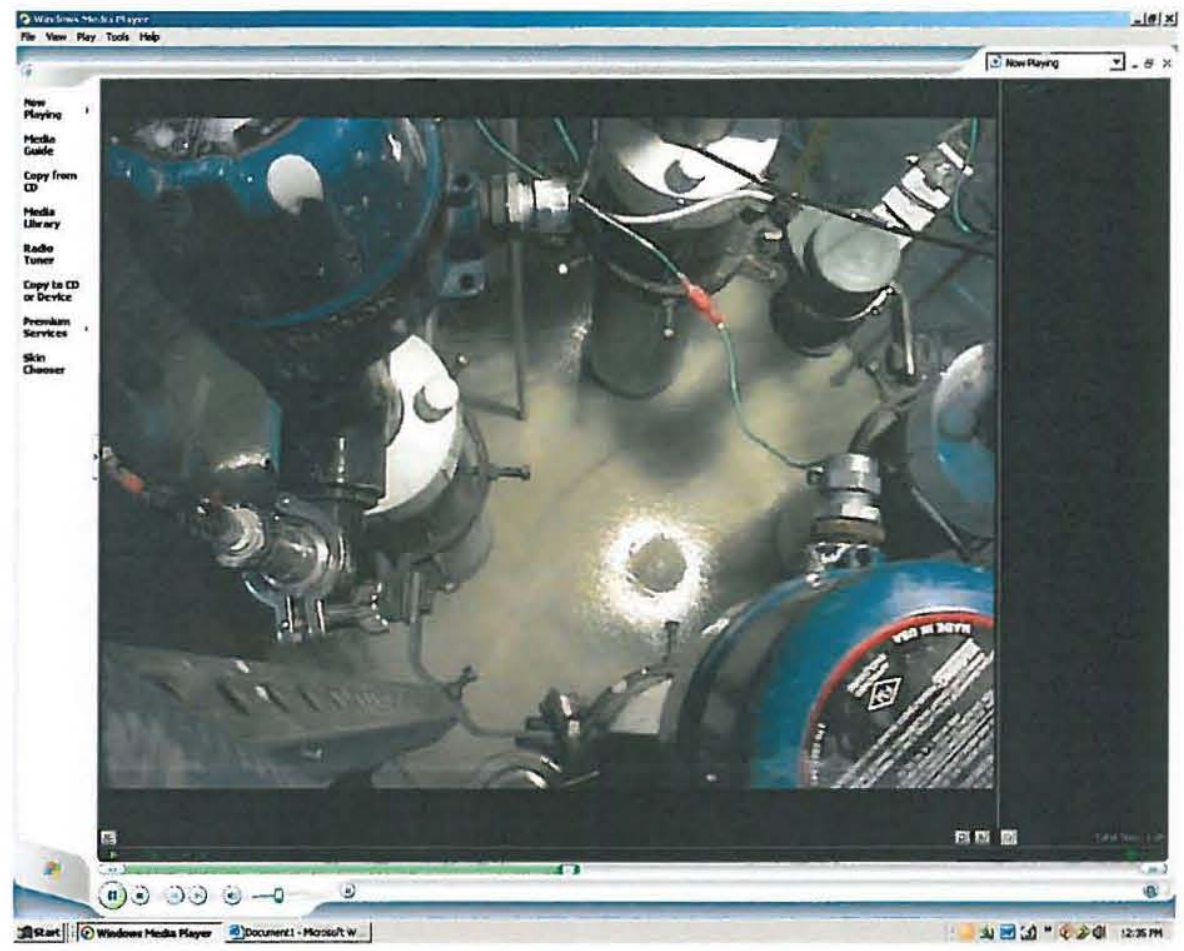

Figure 1. Appearance of a bubble on the surface of a bumped vessel. The still frame shows a bubble of about $6 \mathrm{~cm}$ in diameter emerging from a $0.49 \mathrm{~m}^{3}$ vessel containing an aqueous slurry of kaolin and bentonite particles. Before the perturbation, the fluid was stationary and contained millions of oxygen bubbles generated by $\mathrm{H}_{2} \mathrm{O}_{2}$ decomposition of average diameter $0.3 \mathrm{~cm}$. Bubble coalescence must have occurred to generate the observed bubble since the vessel depth $(0.8 \mathrm{~m})$ is too shallow for significant enlargement by decompression. 


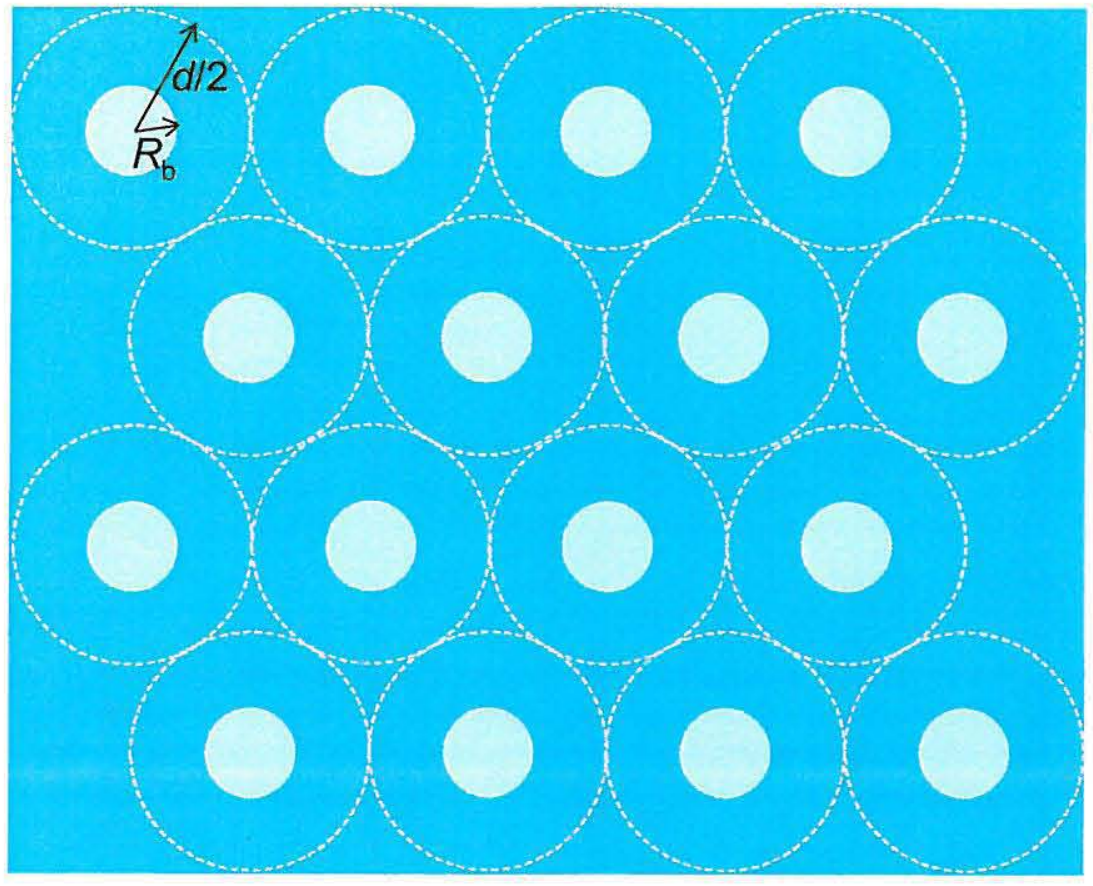

(a)

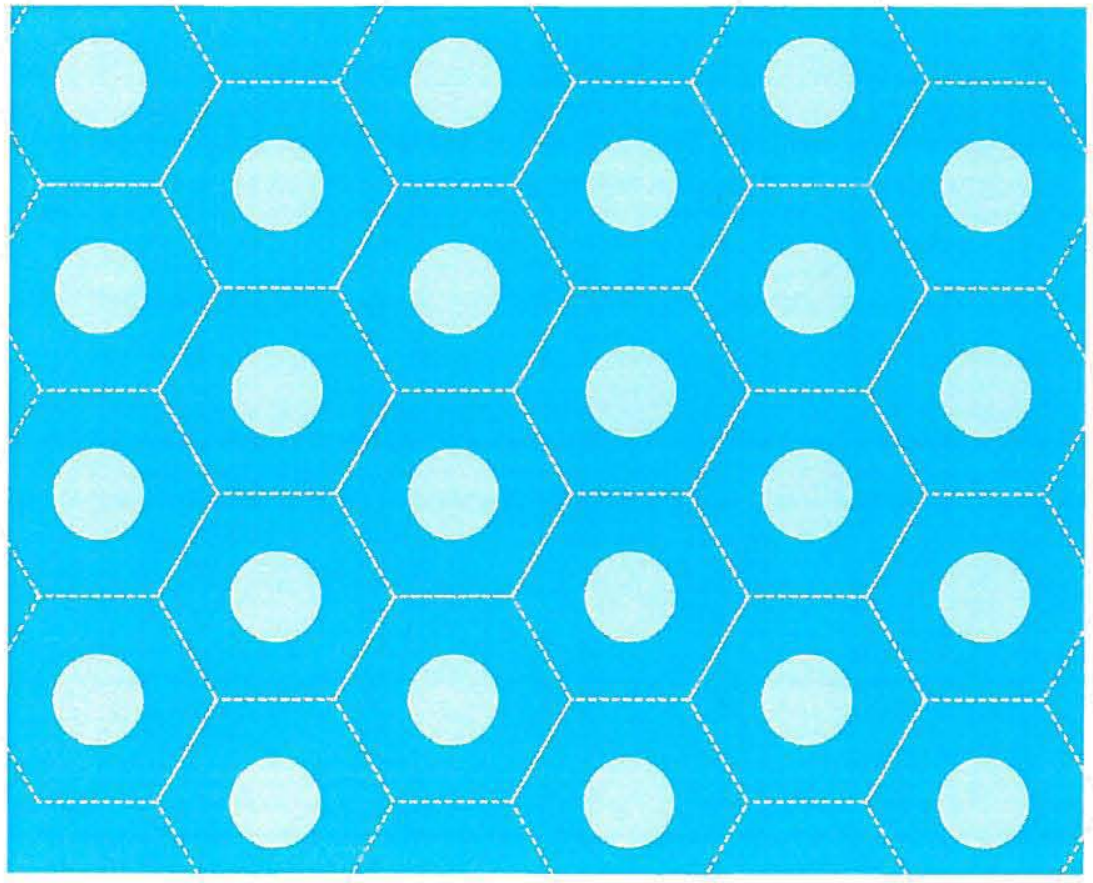

(b)

Figure 2. Models for spatially periodic bubble arrays in gas-liquid emulsions; (a) bubbles are surrounded by a spherical region of fluid of diameter $d$; (b) each bubble is inside a hexagon that inscribes the circles in (a). 


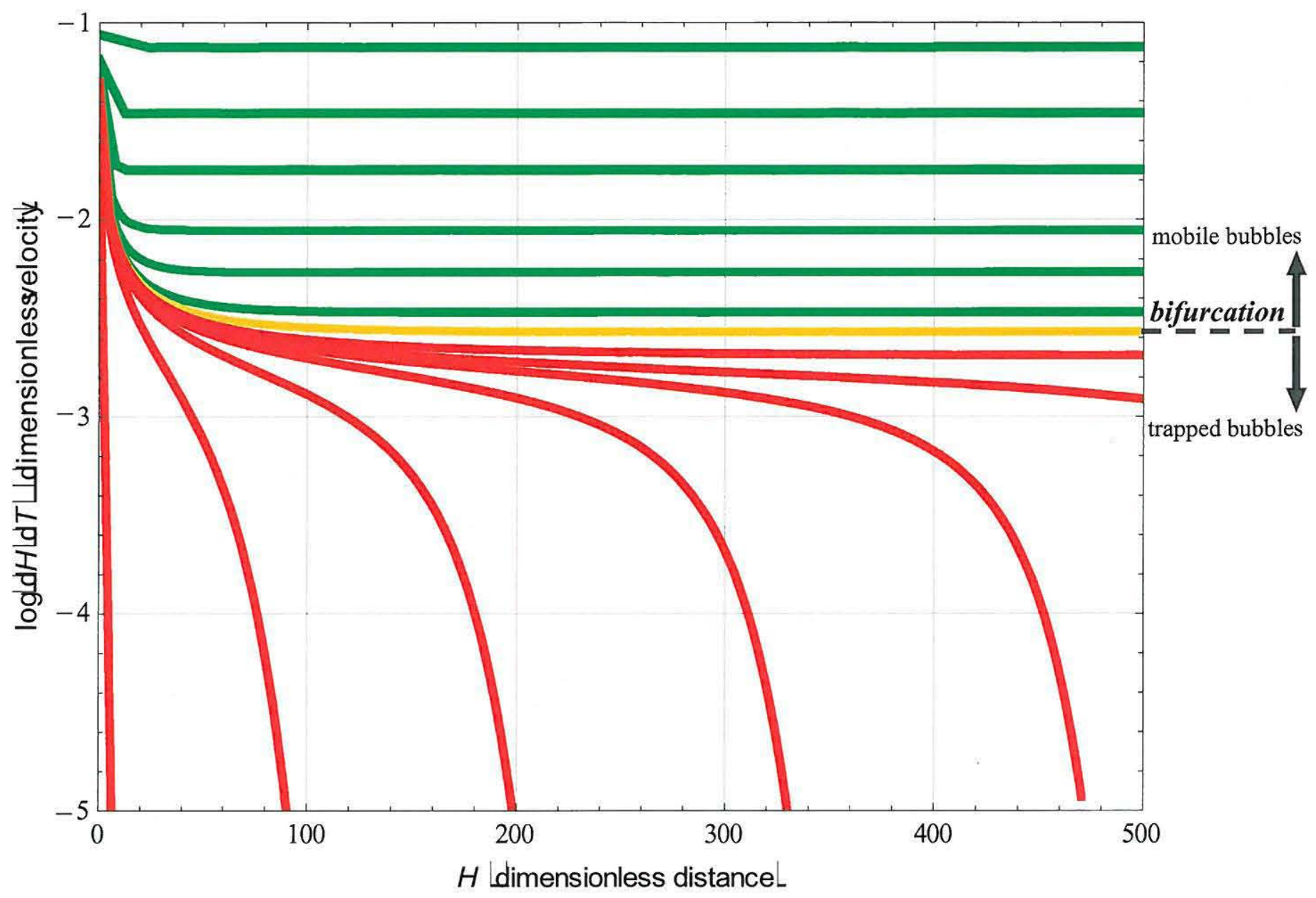

Figure 3. Bubble rise velocity as a function of vertical distance in a yield-stress fluid as represented by the model developed by Ferroir et al. (2004). Parameters used in the simulation: $s^{0}=10 ; \beta=1 ; n=1.02$ (aqueous suspension of laponite and bentonite clays); values of $Y^{\circ}$ shown. For $Y^{\infty} \geq 0.572$, the ascending speed reaches an asymptotic value, indicating that bubbles will continue to rise until they disengage from the suspension. For $Y^{\infty}<0.573$, bubble velocity decreases monotonically so that, given enough fluid depth, bubbles will be trapped. 


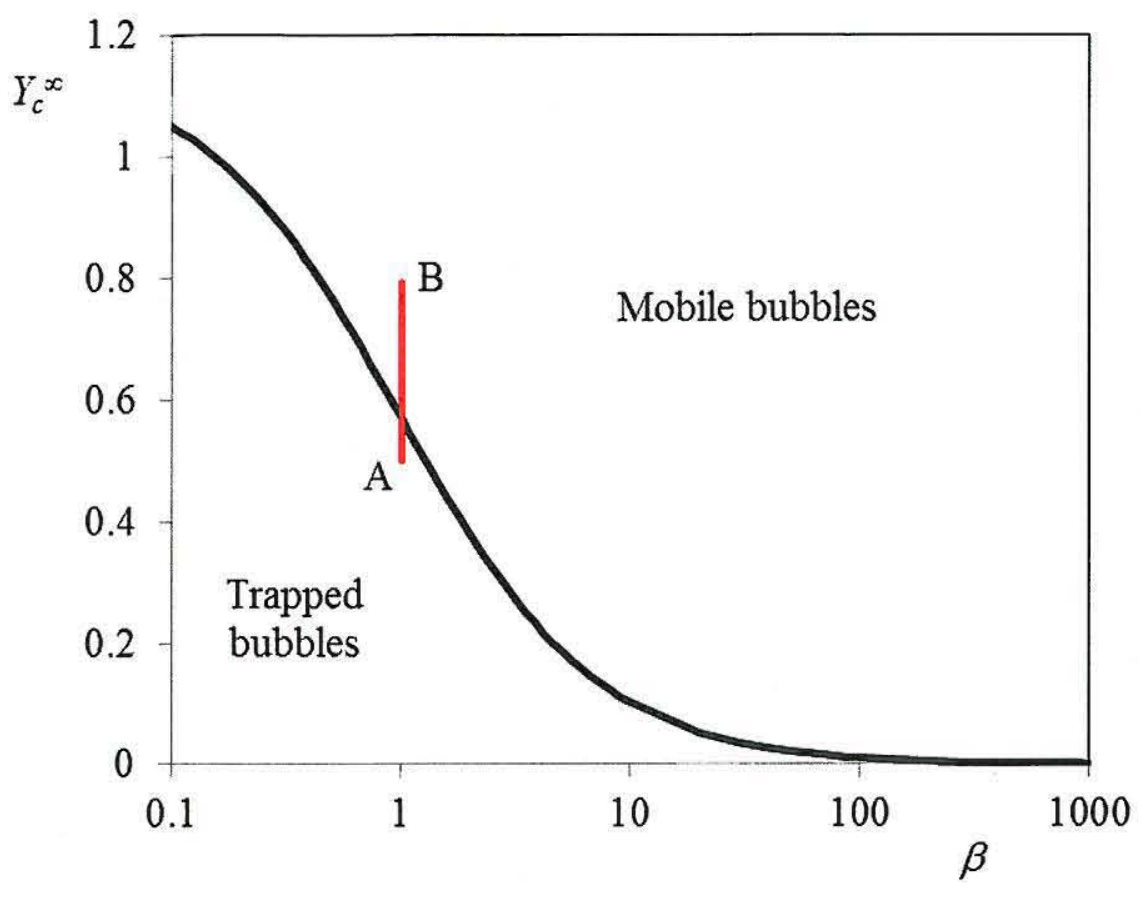

Figure 4. Bubble retention map for $s^{0}=10 ; \beta=1 ; n=1.02$. The solid line represents the critical value of $Y^{\infty}$ above which bubbles will reach a terminal velocity (mobile bubbles) and below which the bubble velocity keeps decreasing with vertical distance (trapped bubbles). The red line illustrates a regime change when two bubbles of radius $R_{b 1}$ with $Y^{\infty}=0.5$ (point $\mathrm{A}$ ) coalesce to form a single bubble of radius $R_{b 2}$ : at constant pressure (i.e. neglecting surface tension effects), $R_{b 2} / R_{b 1}=2^{1 / 3}$, which increases $Y^{\circ}$ to 0.79 (point $\mathrm{B}$ ), since $Y^{\infty} \sim R_{b}{ }^{2}$. This shows how bubbles that potentially may become trapped will lead to ebullition upon coalescence. 

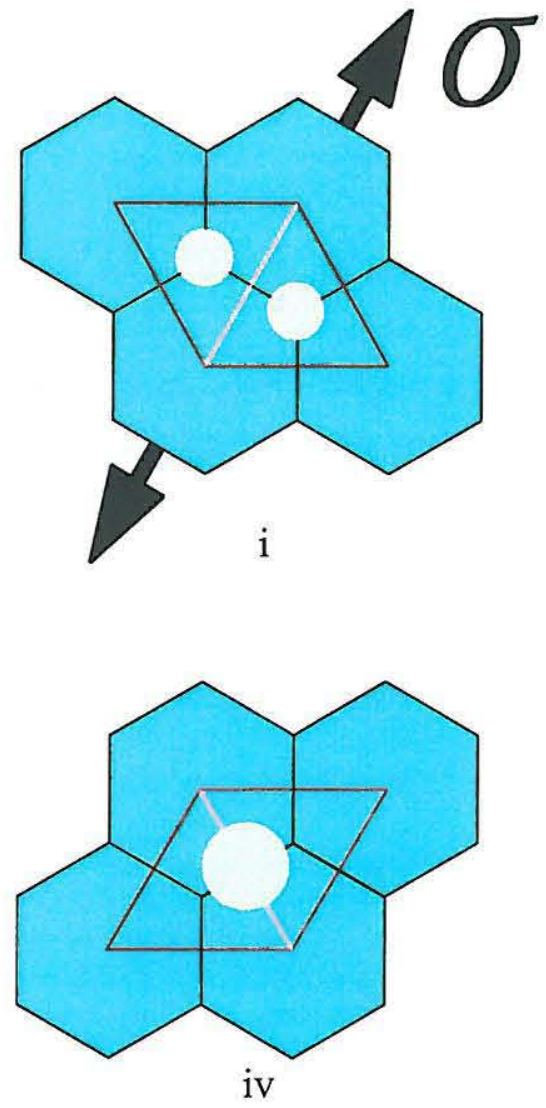
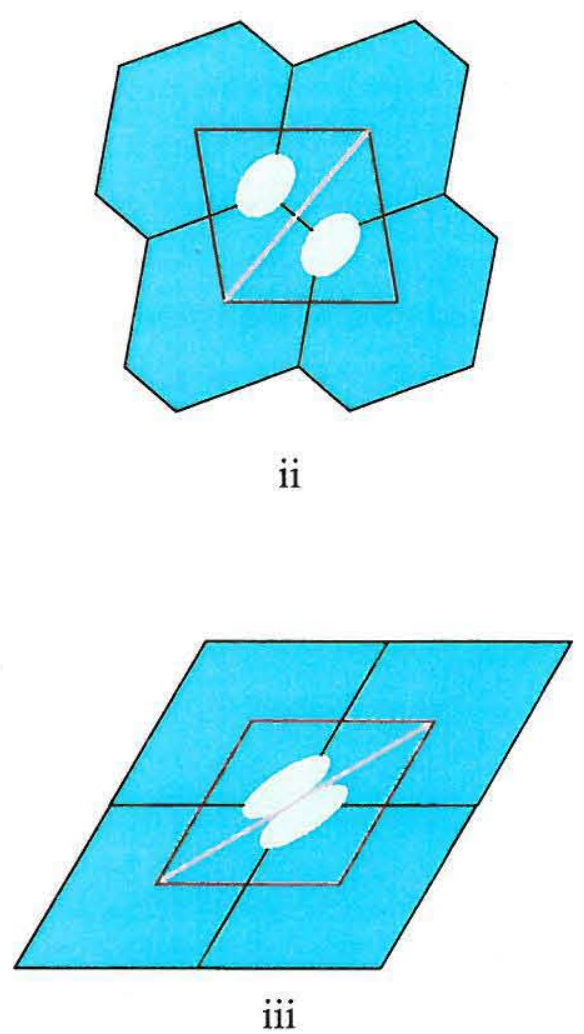

Figure 5. Bubble coalescence from neighbor switching reactions. Hexagons represent the continuous phase, a quasi-static yield-stress fluid, and the small, lightly-shaded circles represent the dispersed second phase (bubbles). The hexagons undergo neighbor switching: i. Initial condition with tensile stress and equivalent shear stress (parallelogram). ii. Fluid elements and bubbles respond elastically to the stress. iii. Fluid elements have stretched to a maximum extent and bubbles have contacted. iv. Final condition: boundaries have relaxed to minimize surface area and the bubbles have merged/relaxed. 


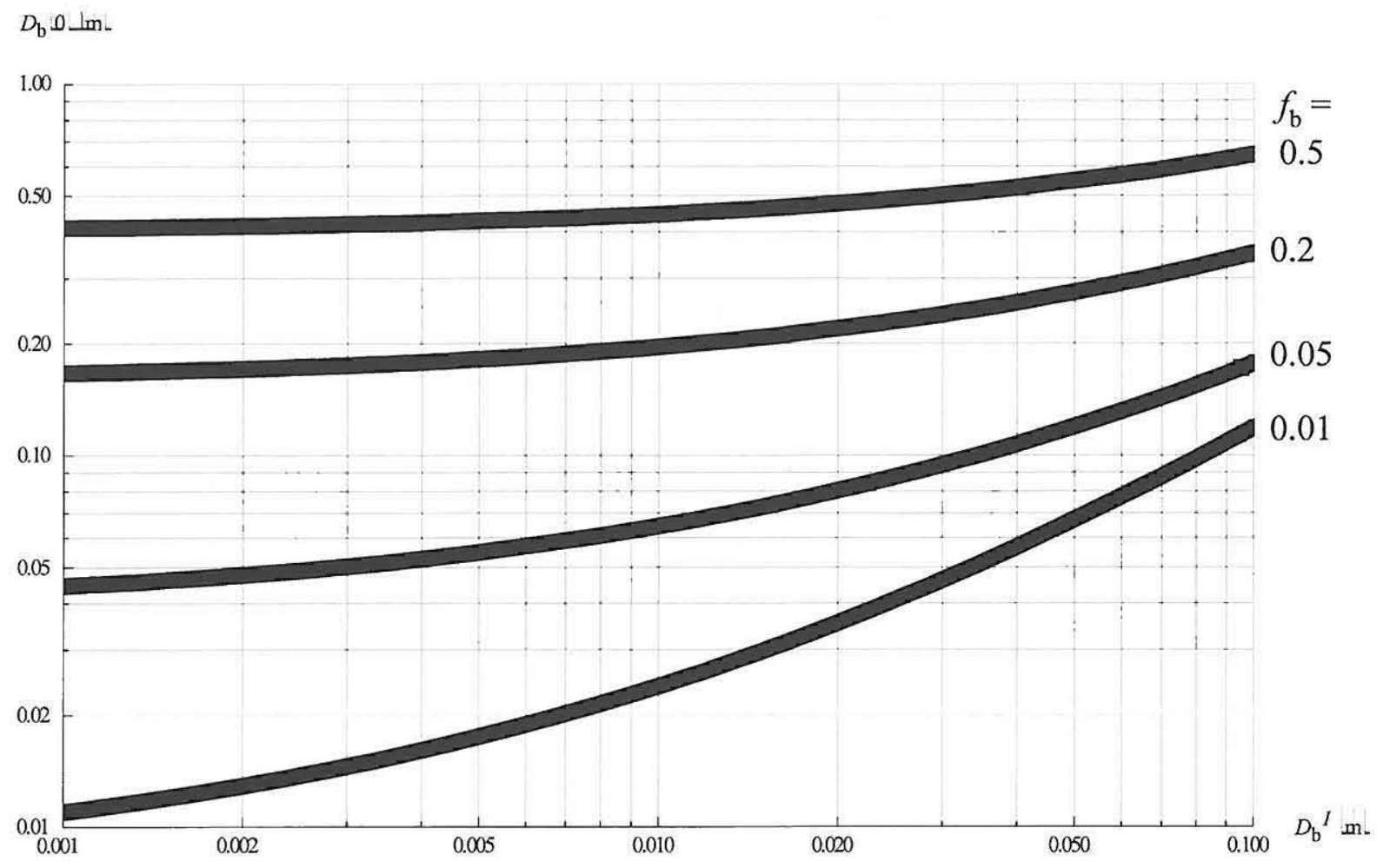

Figure 6. Ebullitive bubble enlargement from cascade coalescence. Bubbles enlarge in a cascade because they collide inelastically with one another and coalesce. Fluid density is $\rho=1,200$ $\mathrm{kg} / \mathrm{m}^{3}$ with various volume fractions. In all four cases shown the bubble cascade begins with a bubble having diameter $\mathrm{D}_{\mathrm{bi}}$, rising from a depth $h=L=0.4 \mathrm{~m}$ to the surface $h=0$, enlarging to attain the value $D_{b}(0)$ (bubble diameter at the surface), which increases as the initial value increases. 